Aging Studies of Filled and Unfilled VCE

S. Letant, C. Alviso, M. Pearson, T. Wilson, S. Chinn, R. Maxwell

April 7, 2011 
This document was prepared as an account of work sponsored by an agency of the United States government. Neither the United States government nor Lawrence Livermore National Security, LLC, nor any of their employees makes any warranty, expressed or implied, or assumes any legal liability or responsibility for the accuracy, completeness, or usefulness of any information, apparatus, product, or process disclosed, or represents that its use would not infringe privately owned rights. Reference herein to any specific commercial product, process, or service by trade name, trademark, manufacturer, or otherwise does not necessarily constitute or imply its endorsement, recommendation, or favoring by the United States government or Lawrence Livermore National Security, LLC. The views and opinions of authors expressed herein do not necessarily state or reflect those of the United States government or Lawrence Livermore National Security, LLC, and shall not be used for advertising or product endorsement purposes.

This work performed under the auspices of the U.S. Department of Energy by Lawrence Livermore National Laboratory under Contract DE-AC52-07NA27344. 


\title{
Aging Studies of Filled and Unfilled VCE
}

\author{
Sonia E. Létant, Cynthia T. Alviso, Mark Pearson, Thomas S. Wilson, Sarah C. \\ Chinn, and Robert S. Maxwell
}

\begin{abstract}
VCE is an ethylene, vinyl acetate, vinyl alcohol elastomer used to bind high volumes of microparticles. Surveillance data for this material is both scarce and scattered, complicating the assessment of any aging trends in systems. In addition, most of the initial surveillance efforts focused on mechanical properties such as hardness and tensile strength, and chemical information is therefore lacking. The initial work conducted in FY09 focused on the effects of gamma radiation up to $25 \mathrm{MR}$ on filled and unfilled VCE material produced by the Kansas City Plant (KCP) using WR-qualified processes. The work performed in FY10 focused on the effects of temperatures up to $150^{\circ} \mathrm{C}$ on the $\mathrm{VCE}$ material produced by $\mathrm{KCP}$, as well as on a comprehensive data integration to generate a mechanistic understanding of degradation mechanisms in the VCE material. A series of structural and chemical characterization techniques were employed including: Toluene Swelling, Tensile Testing, Solid Phase Micro Extraction Gas Chromatography - Mass Spectrometry, Infra-Red Spectroscopy, and UV-vis Spectroscopy. Overall results from FY09 and FY10 show a 'yellowing' of the material, an increased release of acetic acid and an increased Young's modulus with increased temperature and increased gamma irradiation dose. When subjected to gamma radiation, VCE samples also showed increased crosslinking, reduced mobility, and hindered IR deformation modes. These observations may be explained by a model in which acetic acid is eliminated from the vinyl acetate group via a molecular rearrangement in which a Hydrogen atom from the ethylene backbone moves to the acetate group. This mechanism releases acetic acid and forms a $\mathrm{C}=\mathrm{C}$ double bond in the polymer backbone, therefore reducing chain mobility, hindering ethylene deformation modes, affecting the mechanical properties of the VCE material and generating a yellow color through the formation of polyenes. The work showed that acetic acid may constitute an effective chemical signature to probe the aging of VCE material in systems. Future efforts will involve work with actual VCE parts to develop a comprehensive aging model of VCE in systems.
\end{abstract}




\section{Table of Contents}

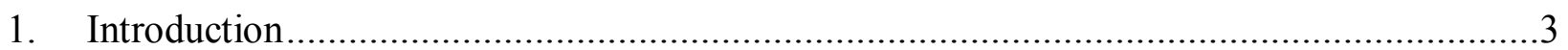

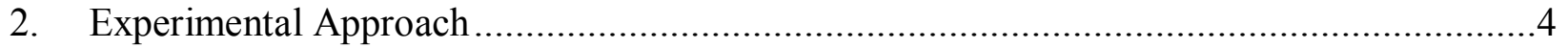

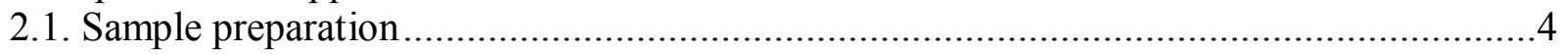

2.2. Solid Phase Micro Extraction - Gas Chromatography / Mass Spectrometry .......................5

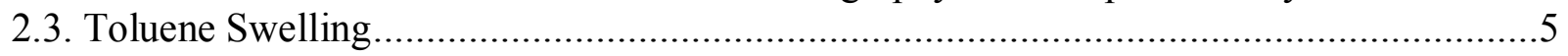

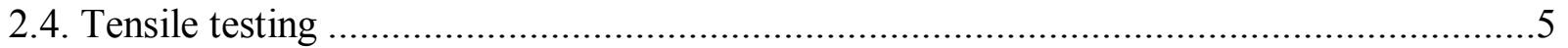

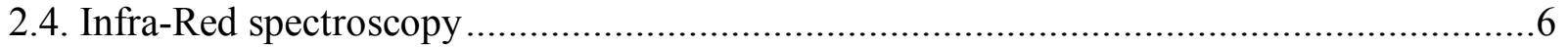

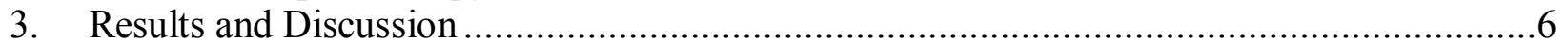

3.1. Solid Phase Micro Extraction - Gas Chromatography / Mass Spectrometry .......................6

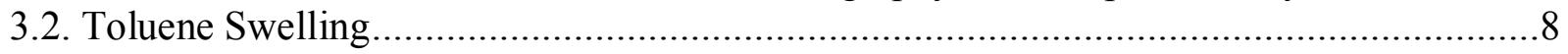

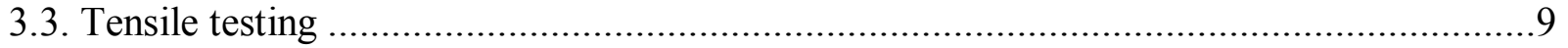

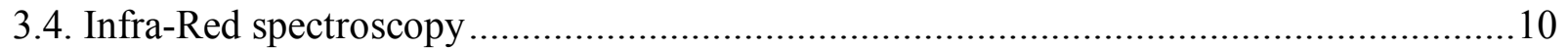

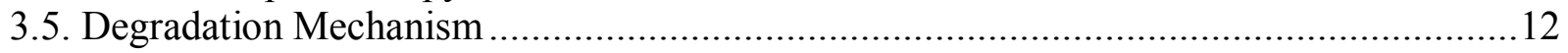

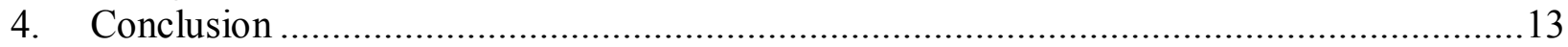

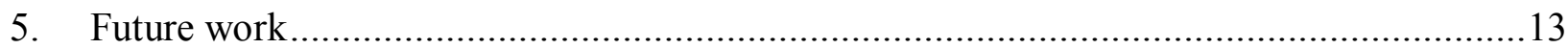

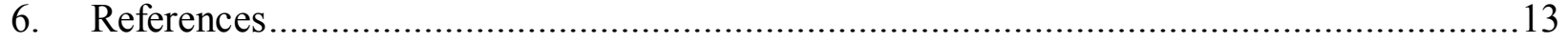




\section{Introduction}

VCE is an ethylene/vinyl acetate/vinyl alcohol terpolymer binder for filled elastomers (Figure 1) which is designed to accept high filler loadings. Filled elastomer parts consist of the binder (VCE), a curing agent (Hylene MP, diphenol-4,4'-methylenebis(phenylcarbamate)), a processing aid (LS, lithium stearate), and filler particles (typically $70 \%$ fraction by weight). The curing of the filled elastomer parts occurs from the heat-activated reaction between the hydroxyl groups of VCE with the Hylene MP curing agent, resulting in a cross-linked network (Figure 2). The final vinyl acetate content is between 34.9 and $37.9 \%$, while the vinyl alcohol content is between 1.27 and $1.78 \%$.

Surveillance data for this material is both scarce and scattered, complicating the assessment of any aging trends in systems. In addition, most of the initial surveillance efforts focused on mechanical properties such as hardness and tensile strength, and chemical information is therefore lacking.

Material characterization and aging studies had been performed on previous formulations of the VCE material [1-2] but the Ethylene Vinyl Acetate (EVA) starting copolymer is no longer commercially available. New formulations with replacement EVA materials are currently being established and will require characterization as well as updated aging models [3, 4].

The initial work conducted in FY09 focused on the effects of gamma radiation up to $25 \mathrm{MR}$ on the chemical and structural properties of filled and unfilled VCE material synthesized, milled, molded and cured by the Kansas City Plant (KCP) using WR-qualified processes (see KCP-6136051), as well as initial results with thermally-aged samples. The work performed in FY10 and presented in this report focuses on the effects of temperatures up to $150^{\circ} \mathrm{C}$ on the VCE material produced by $\mathrm{KCP}$, and on additional measurements on samples exposed to gamma radiation. A comprehensive data integration was also performed in order to generate a mechanistic understanding of degradation mechanisms in the VCE material, which sparked a collaboration with David Plant and Mark Read at AWE, who are using Density Functional Theory (DFT) to calculate the lowest energy configurations of a similar polymer used in the UK, as well as corresponding IR spectra. A manuscript is in preparation, to be submitted to the Journal of Polymer Degradation in a few months.
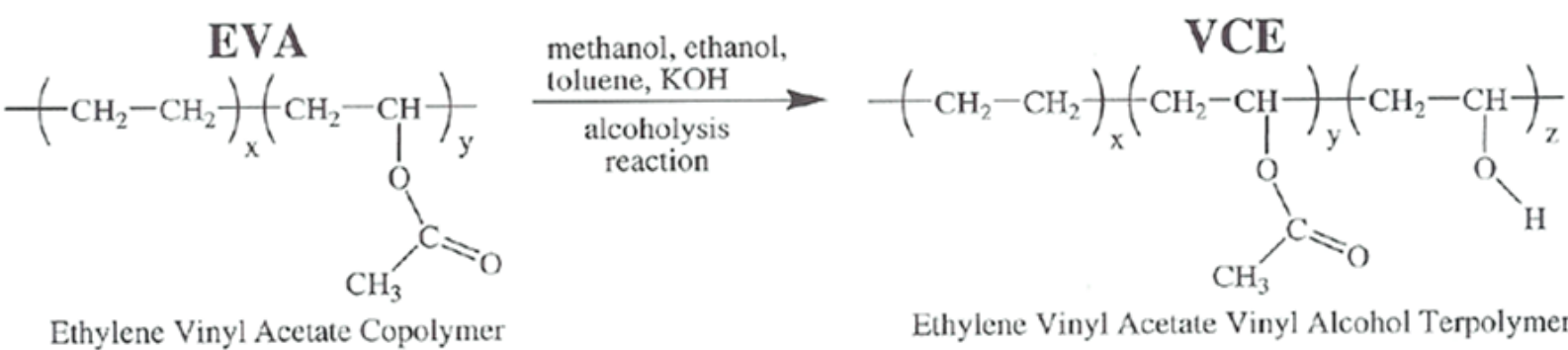

Ethylene Vinyl Acetate Vinyl Alcohol Terpolymer

Figure 1: Base-catalyzed alcoholysis reaction of EVA copolymer yielding VCE [3]. Typical VCE composition is $34.9-37.9 \%$ vinyl acetate, and $1.27-1.78 \%$ hydroxyl. 

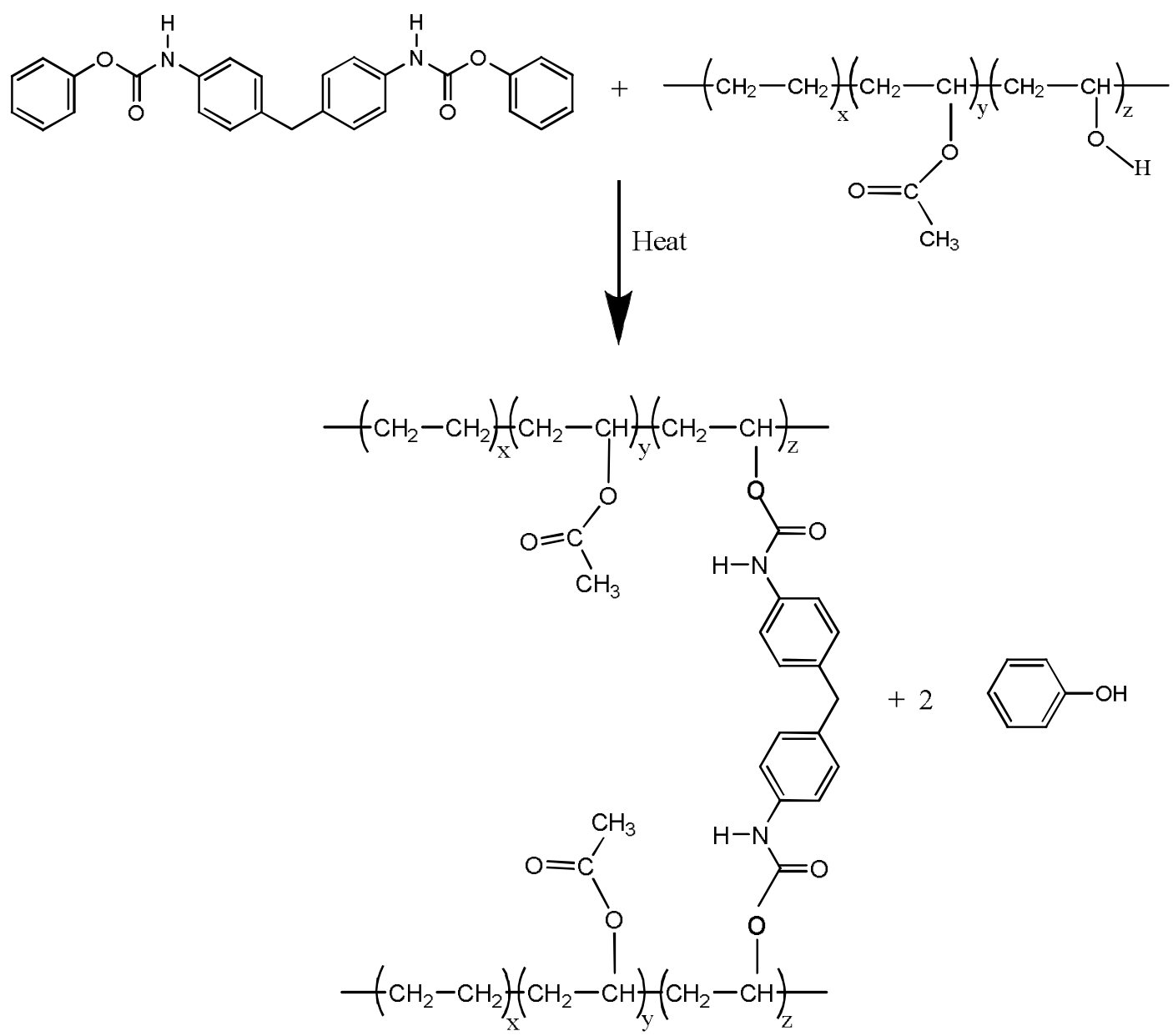

Figure 2: Curing reaction between VCE and Hylene MP [3].

\section{Experimental Approach}

\subsection{Sample preparation}

VCE samples were synthesized via alcoholysis of EVA in the presence of sodium hydroxide. The material used in this study was custom-synthesized at Honeywell Federal Manufacturing \& Technologies, Kansas City, MO, with a vinyl alcohol content of $1.5 \%$ and a vinyl acetate content of $35 \%$. After blending with $10 \%$ diphenol-4-4',-methylenebis(phenylcarbamate) and $1-2 \%$ lithium stearate (used as a lubricant) on a 2-roll mill, the VCE material was injected in molds and cured at $179^{\circ} \mathrm{C}$ for $30 \mathrm{~min}$, resulting in the cross-linked network shown in Figure 2. Phenol released during the cross-linking reaction was removed using a thermal post-cure treatment at $120^{\circ} \mathrm{C}$ for $5 \mathrm{hr}$.

VCE sheets with a diameter of 11 " and a thickness of 0.030 " were checked for uniformity using X-ray radiography and packaged with desiccant and heat-sealed sleeves prior to shipping to LLNL.

Identical samples were maintained in dry conditions, sealed into plastic bags, placed into a stainless steel vessel and exposed to a $1.2 \mathrm{MeV}, 5 \mathrm{kGray} /$ hour, ${ }^{60} \mathrm{Co}$ gamma-ray source. The final gamma irradiation doses generated for this study were $10 \mathrm{kGray}(1 \mathrm{MRad})$ and $250 \mathrm{kGray}(25$ 
MRad) respectively. A set of samples was also thermally aged for $24 \mathrm{hr}$ at 50, 100, 125, 150, $175,200,250$ and $300{ }^{\circ} \mathrm{C}$ respectively, using a muffle furnace. Another set of samples was thermally aged under inert conditions at 20,70 and $150^{\circ} \mathrm{C}$, and held at these respective temperatures for 1 and 7 months respectively. Degraded samples were analyzed alongside pristine samples.

\subsection{Solid Phase Micro Extraction - Gas Chromatography / Mass Spectrometry (SPME-GC/MS)}

VCE samples (20-30 mg each) were placed in $20 \mathrm{~mL}$ SPME headspace glass vials, and sealed under nitrogen with crimp caps and septa $(20 \mathrm{~mm}$, Teflon/blue silicone, level 4, MicroLiter Analytical Supplies Inc., Suwanee, GA).

For radiation-aged samples, and samples aged in the muffle furnace, 5 replicates were left at room temperature and another 5 replicates were placed in an oven at $150^{\circ} \mathrm{C}$. All samples remained at their designated temperatures for two weeks. An additional set of references (sealed empty vials) was also prepared for storage at room temperature and $150^{\circ} \mathrm{C}$ prior to SPME sampling. The storage at elevated temperatures was performed to maximize the volatilization of degradation signatures for observation by SPME sampling, while retaining room temperature samples and blanks to serve as controls.

For the holding study, 5 VCE samples were held at $20^{\circ} \mathrm{C}, 15$ samples were held at $70^{\circ} \mathrm{C}$, and 15 samples were held at $150^{\circ} \mathrm{C}$. Five samples were analyzed after 2 weeks, 5 samples were analyzed after 1 month, and the last 5 samples were analyzed after 7 months.

Samples were analyzed by SPME-GC-MS using an automated GC-MS system (GC model 6890 and MS model 5973, both from Agilent Technologies Inc., Santa Clara, CA) with the following conditions: $85 \mu \mathrm{m}$ Carboxen/Polydimethylsiloxane SPME fiber (Sigma-Aldrich Inc., St. Louis, MO), conditioned between samples for $5 \mathrm{~min}$ at $260{ }^{\circ} \mathrm{C}$. Each vial headspace was sampled at $50^{\circ} \mathrm{C}$ for $20 \mathrm{~min}$ and injected into the $\mathrm{GC}$ for $1 \mathrm{~min}$ at $250^{\circ} \mathrm{C}$. The $\mathrm{GC}$ was set for 'splitless' injection and purged for $0.5 \mathrm{~min}$ with a constant $1.0 \mathrm{~mL} / \mathrm{min}$ flow of helium. The column used for these experiments was designed for volatile analysis $(30 \mathrm{~m}, 0.25 \mathrm{~mm}$ ID, 1.4 $\mu \mathrm{m}$ film, DB-624, Agilent Technologies Inc., Santa Clara, CA). Each $20 \mathrm{~min}$ run had the following temperature profile: $40^{\circ} \mathrm{C}$ hold for $1.05 \mathrm{~min}, 23.41^{\circ} \mathrm{C} / \mathrm{min}$ ramp to $260^{\circ} \mathrm{C}$, and $260^{\circ} \mathrm{C}$ hold for $6.81 \mathrm{~min}$. The MS scanned the mass range from $35-450 \mathrm{~m} / \mathrm{z}$ at a rate of $1.81 \mathrm{scans} / \mathrm{s}$ without filament delay. Materials outgassing from the VCE samples were identified by comparison of their mass spectra to the NIST 02 mass spectral library.

\subsection{Toluene Swelling}

VCE samples were cut into pieces weighing approximately $150 \mathrm{mg}$. Each piece was weighed with $\mathrm{mg}$ precision before being placed into a $40 \mathrm{~mL}$ glass vial and submerged with toluene. Vials were sealed and samples were let to swell for $24 \mathrm{hr}$. The next day, samples were removed from the vial, quickly dried with absorbent paper, and weighed a second time. Three replicates were analyzed for each set of experimental conditions.

\subsection{Tensile testing}

Mechanical measurements were made on an Instron (Model 5500-R) using a $10 \mathrm{lb}$ load cell equipped with pneumatic grips. Test samples were cut from the pristine or aged material to ASTM D-638 Type V dogbones using a punch. Materials were assumed to have a nominal thickness of 30 mils $(0.762 \mathrm{~mm})$. Testing was perfromed using a grip separation of $25.4 \mathrm{~mm}$, 
which was used as the gage length for all calculations. For each sample (material/preparation condition), 5 specimens (replicates) were tested to failure at a crosshead speed of $0.5 \mathrm{in} / \mathrm{minute}$.

\subsection{Infra-Red spectroscopy}

Infra-red spectra were acquired using a Bruker Hyperion spectrometer fitted with a $20 \mathrm{X}$ Attenuated Total Reflectance (ATR) objective, and a pressure setting of 3 (out of 5). All the spectra presented in this report were acquired using the same settings. Five replicate samples were analyzed for each set of experimental conditions and representative spectra are presented (there were generally no statistical differences between replicate spectra).

\section{Results and Discussion}

\subsection{Solid Phase Micro Extraction - Gas Chromatography / Mass Spectrometry (SPME-GC/MS)}

SPME-GC/MS experiments were performed on gamma-irradiated samples held at room temperature, and on a duplicate sample set held at $150^{\circ} \mathrm{C}$ (storage at elevated temperatures was performed in order to maximize the volatilization of degradation products). Figure 3 shows GCMS spectra of unfilled VCE samples exposed to various doses of radiation before being held in vials for 2 weeks at $150^{\circ} \mathrm{C}$. The main outgassing chemicals identified were: silanol, acetic acid, butanoic acid, propanoic acid, and phenol (ranked according to their retention times).

The main peak, identified as acetic acid according to the NIST 02 mass spectrometry library, was confirmed by performing SPME-GS-MS on a vial spiked with acetic acid (identical retention times were obtained). Although the method is not quantitative, integrated peak areas are reported for acetic acid in Table 1, to provide a qualitative indication of the effects of temperature and irradiation on the outgassing of acetic acid from the VCE material. This approach relied on the fact that all samples were analyzed in a single batch, without tuning the instrument between samples. As seen in Table 1, no acetic acid evolution was observed at room temperature without irradiation, but the release of this chemical qualitatively increased with both temperature and irradiation independently.

In another study, filled VCE samples were held under inert atmosphere in SPME-GC-MS vials at 20,70 and $150^{\circ} \mathrm{C}$ for 1 and 7 months respectively. The corresponding data, presented in Table 2, showed no significant outgassing at room temperature. The amount of acetic acid outgassed from the samples increased with temperature, but at a fixed temperature the acetic release appeared to plateau after 1 month, indicating that most of the outgassing occurred during the first weeks of thermal aging. Again, it should be noted that SPME-GC-MS is not a quantitative technique and that these observations are mostly qualitative.

Propanoic and butanoic acids were detected in low abundance at high temperature and/or high gamma irradiation doses and may be fragments of the lithium stearate processing aid. Phenol, also detected in low abundance, is a degradation product of the crosslinking agent (see Scheme 1) used in the synthesis of VCE, resulting from thermal unblocking of urethane. Finally, the presence of low concentrations of silanol was attributed to the outgassing of silicone used for mold release during the curing of the VCE samples 


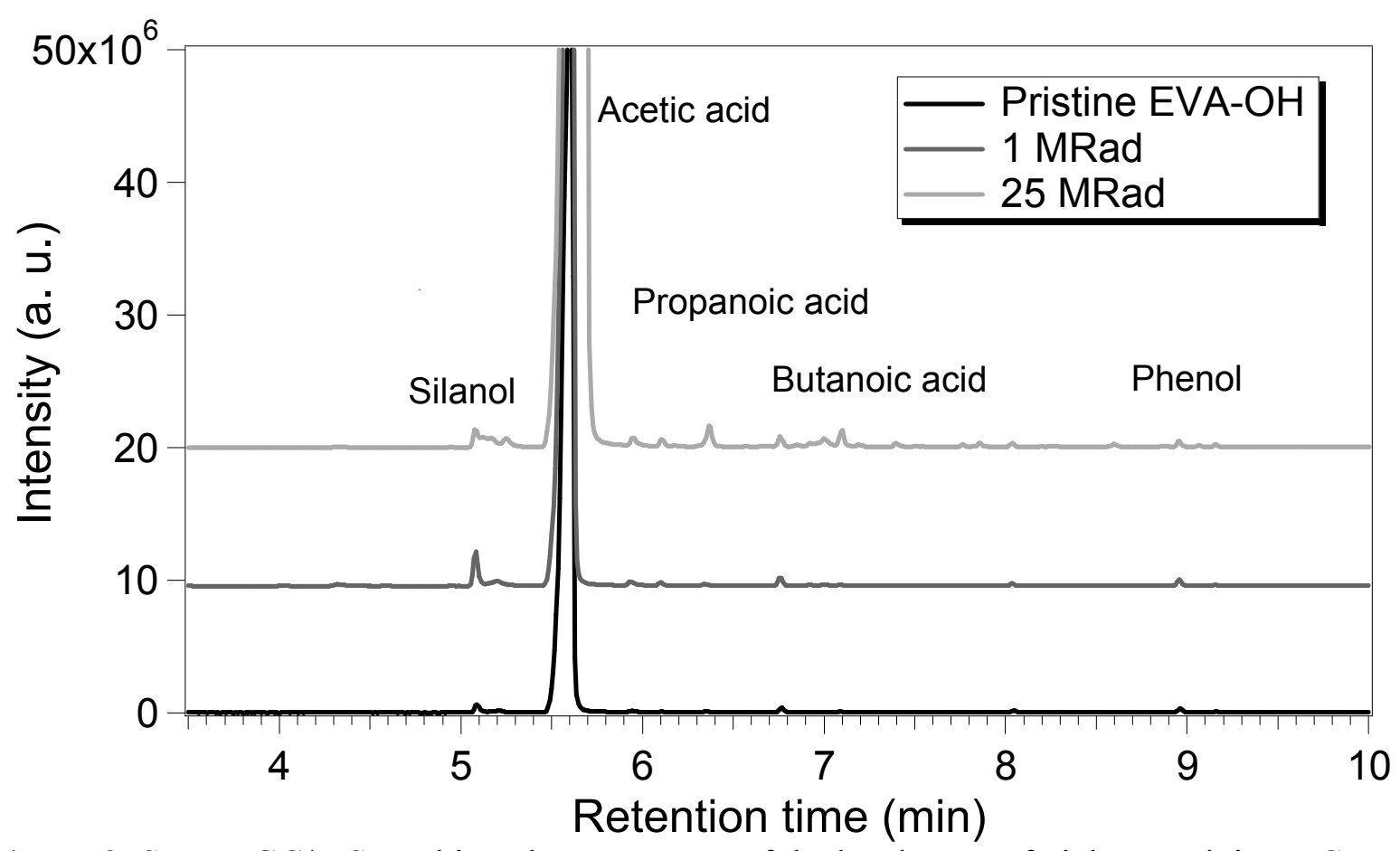

Figure 3. SPME-GC/MS total ion chromatogram of the headspace of vials containing VCE samples exposed to gamma irradiation doses of 0,1 and 25 MRad. Samples were held at a constant temperature of $150^{\circ} \mathrm{C}$ for 2 weeks.

Table 1. SPME-GC/MS analysis of acetic acid evolution from unfilled VCE samples exposed to thermal degradation at $150^{\circ} \mathrm{C}$ and gamma irradiation doses of 0,1 and $25 \mathrm{MRad}$. Total ion chromatogram peak areas are reported for each set of experimental conditions. Results from 5 replicate samples were averaged and corresponding standard deviations are provided.

\section{Gamma}

Irradiation

0

1

25

\begin{tabular}{|c|c|c|c|c|c|c|c|}
\hline \multirow{2}{*}{$\begin{array}{c}\text { Experimental } \\
\text { Conditions }\end{array}$} & \multicolumn{7}{|l|}{ Dose (MRad) } \\
\hline & $\begin{array}{c}\text { Thermal Aging } \\
\text { Temperature } \\
\left({ }^{\circ} \mathrm{C}\right)\end{array}$ & 20 & 150 & 20 & 150 & 20 & 150 \\
\hline \multirow{2}{*}{$\begin{array}{l}\text { Acetic acid } \\
\text { outgassing }\end{array}$} & $\begin{array}{c}\text { Acetic acid } \\
\text { peak area } \\
\text { (a. u.) }\end{array}$ & 0 & $2.210^{9}$ & $1.510^{7}$ & $2.810^{9}$ & $1.210^{9}$ & $5.810^{9}$ \\
\hline & $\begin{array}{r}\text { Standard } \\
\text { deviation } \\
\text { (a. u.) }\end{array}$ & 0 & $6.010^{8}$ & $5.010^{6}$ & $7.010^{8}$ & $2.010^{8}$ & $7.010^{8}$ \\
\hline
\end{tabular}


Table 2. SPME-GC/MS analysis of acetic acid evolution from filled VCE samples exposed to thermal degradation at 20,70 and $150^{\circ} \mathrm{C}$ for 1 and 7 months, under inert atmosphere. Total ion chromatogram peak areas are reported for each set of experimental conditions. Results from 5

replicate samples were averaged and corresponding standard deviations are provided.

\begin{tabular}{|c|c|c|c|c|c|c|c|}
\hline \multirow{2}{*}{$\begin{array}{c}\text { Experimental } \\
\text { Conditions }\end{array}$} & $\begin{array}{c}\text { Thermal } \\
\text { Aging } \\
\text { Temperature } \\
\left({ }^{\circ} \mathrm{C}\right) \\
\end{array}$ & \multicolumn{2}{|c|}{20} & \multicolumn{2}{|c|}{70} & \multicolumn{2}{|c|}{150} \\
\hline & Time (months) & 1 & 7 & 1 & 7 & 1 & 7 \\
\hline \multirow{2}{*}{$\begin{array}{l}\text { Acetic acid } \\
\text { outgassing }\end{array}$} & $\begin{array}{c}\text { Acetic acid } \\
\text { peak area } \\
\text { (a. u.) } \\
\end{array}$ & 0 & 0 & $1.010^{7}$ & $7.010^{6}$ & $1.410^{9 *}$ & $1.810^{9^{*}}$ \\
\hline & $\begin{array}{c}\text { Standard } \\
\text { deviation } \\
\text { (a. u.) }\end{array}$ & 0 & 0 & $5.010^{6}$ & $1.810^{6}$ & $4.010^{8}$ & $1.010^{9}$ \\
\hline
\end{tabular}

*Saturation of the acetic acid peak is observed on some of the spectra.

\subsection{Toluene Swelling}

Toluene swelling experiments were performed in order to assess the level of cross-linking in the VCE material. A slight decrease in swell ratio was measured for irradiated samples (see Table 3), which is attributed to an increased cross-linking upon radical formation in the material. No statistical difference was observed on thermally-treated samples (see Table 4), indicating no significant change in the cross-linking of the material upon thermal aging.

Table 3. Toluene swell ratio $\left(\mathrm{V} / \mathrm{V}_{0}\right)$ of filled and unfilled VCE samples exposed to gamma irradiation doses of 0,1 and $25 \mathrm{MRad}$. W2/W1 is the ratio of the masses of the swollen and dry EVA-OH materials. The swell ratio $\mathrm{V} / \mathrm{V}_{0}=1.314(\mathrm{~W} 2 / \mathrm{W} 1)-0.314$. Each value represents the average of 3 replicate samples.

\begin{tabular}{cccc}
\hline Filler & $\begin{array}{c}\text { Gamma } \\
\text { Irradiation Dose } \\
\text { (MRad) }\end{array}$ & $\begin{array}{c}\text { Swell Ratio } \\
\text { (V/Vo) }\end{array}$ & $\begin{array}{c}\text { Standard } \\
\text { Deviation }\end{array}$ \\
\hline \multirow{3}{*}{ Unfilled } & 0 & 5.11 & 0.03 \\
& 1 & 5.07 & 0.09 \\
Filled & 25 & 4.52 & 0.01 \\
\hline & 0 & 3.00 & 0.01 \\
\hline
\end{tabular}


Table 4. Toluene swell ratio $\left(\mathrm{V} / \mathrm{V}_{0}\right)$ of filled VCE samples exposed to temperatures of 20,70 and $150^{\circ} \mathrm{C}$ for 1 month under inert atmosphere. W2/W1 is the ratio of the masses of the swollen and dry EVA-OH materials. The swell ratio $\mathrm{V} / \mathrm{V}_{0}=1.314(\mathrm{~W} 2 / \mathrm{W} 1)-0.314$. Each value represents the average of 3 replicate samples.

\begin{tabular}{cccc}
\hline Filler & Thermal treatment & $\begin{array}{c}\text { Swell Ratio } \\
(\mathbf{V} / \text { Vo) }\end{array}$ & $\begin{array}{c}\text { Standard } \\
\text { Deviation }\end{array}$ \\
\hline Filled & 1 month $20^{\circ} \mathrm{C}$ & 3.00 & 0.01 \\
& 1 month at $70^{\circ} \mathrm{C}$ & 3.00 & 0.01 \\
& 1 month at $150^{\circ} \mathrm{C}$ & 3.07 & 0.02 \\
\hline
\end{tabular}

\subsection{Tensile testing}

Tensile testing performed on gamma-irradiated VCE samples showed no statistical difference between pristine and irradiated samples for unfilled material, but filled VCE samples showed a decrease in tensile strength and an increase in Young's modulus upon gamma irradiation (see Table 5).

Tensile testing performed on thermally aged, filled VCE samples showed a significant increase in both tensile strength and Young's modulus upon thermal aging after 1 and 7 months (see Tables 6 and 7). It should be noted that no mechanical measurements were performed on samples aged for 7 months at $150^{\circ} \mathrm{C}$. These samples were distorted and too brittle to handle.

Table 5. Mechanical properties of filled and unfilled VCE samples exposed to gamma irradiation doses of 0, 1 and $25 \mathrm{MRad}$. Results from 5 replicates were averaged and standard deviations are provided.

\begin{tabular}{cccc}
\hline Samples & $\begin{array}{c}\text { Gamma Irradiation } \\
\text { (MR) }\end{array}$ & $\begin{array}{c}\text { Tensile strength } \\
\text { (psi) }\end{array}$ & $\begin{array}{c}\text { Young's modulus } \\
\text { (psi) }\end{array}$ \\
\hline \multirow{2}{*}{ Unfilled VCE } & 0 & $697 \pm 207$ & $680 \pm 27$ \\
& 1 & $887 \pm 74$ & $661 \pm 26$ \\
Filled VCE & 25 & $822 \pm 138$ & $691 \pm 17$ \\
& 0 & $1183 \pm 41$ & $10971 \pm 679$ \\
& 1 & $1112 \pm 22$ & $10872 \pm 890$ \\
\hline
\end{tabular}


Table 6. Mechanical properties of filled VCE samples exposed to temperatures of 20,70 and $150^{\circ} \mathrm{C}$ for 1 month under inert atmosphere. Results from 5 replicates were averaged and standard deviations are provided.

\begin{tabular}{|c|c|c|c|}
\hline Samples & $\begin{array}{l}\text { Thermal treatment } \\
\qquad\left({ }^{\circ} \mathrm{C}\right)\end{array}$ & $\begin{array}{l}\text { Tensile strength } \\
\text { (psi) }\end{array}$ & $\begin{array}{l}\text { Young's modulus } \\
\text { (psi) }\end{array}$ \\
\hline \multirow{3}{*}{ Filled VCE } & 1 month $20^{\circ} \mathrm{C}$ & $1183 \pm 41$ & $10971 \pm 679$ \\
\hline & 1 month at $70^{\circ} \mathrm{C}$ & $1216 \pm 49$ & $13879 \pm 605$ \\
\hline & 1 month at $150^{\circ} \mathrm{C}$ & $1301 \pm 46$ & $15994 \pm 863$ \\
\hline \multicolumn{4}{|c|}{$\begin{array}{l}\text { Table 7. Mechanical properties of filled VCE samples exposed to temperatures of } 20,70 \text { and } \\
150^{\circ} \mathrm{C} \text { for } 7 \text { months under inert atmosphere. Results from } 5 \text { replicates were averaged and } \\
\text { standard deviations are provided. }\end{array}$} \\
\hline Samples & $\begin{array}{c}\text { Thermal treatment } \\
\left({ }^{\circ} \mathrm{C}\right)\end{array}$ & $\begin{array}{l}\text { Tensile strength } \\
\text { (psi) }\end{array}$ & $\begin{array}{l}\text { Young's modulus } \\
\text { (psi) }\end{array}$ \\
\hline \multirow{3}{*}{ Filled VCE } & 7 month $20^{\circ} \mathrm{C}$ & $1183 \pm 41$ & $10971 \pm 679$ \\
\hline & 7 month at $70^{\circ} \mathrm{C}$ & $1102 \pm 35$ & $13192 \pm 1128$ \\
\hline & 7 month at $150^{\circ} \mathrm{C}$ & Sample too brittle & Sample too brittle \\
\hline
\end{tabular}

\subsection{Infra-Red spectroscopy}

IR absorption spectra recorded with an ATR system showed no significant changes in the overall structure of the VCE material after gamma irradiation (see Figure 4). Peaks were indexed as follows: (1) stretching and bending modes from vinyl acetate groups, (2) stretching modes from vinyl alcohol groups, (3) stretching modes from methylene backbone, (4) deformation modes from methylene backbone, (5) bending modes from aromatic groups, and (6) stretching modes from $\mathrm{C}=\mathrm{C}$ and $\mathrm{C}=\mathrm{O}$ bonds. While most of the peaks remained unchanged after gamma irradiation, one of the methylene backbone deformation modes, centered at $1460 \mathrm{~cm}^{-1}$, was significantly hindered after exposure to gamma irradiation for the unfilled VCE material, which is consistent with a decreased mobility of the methylene groups. A slight increase in intensity of the $\mathrm{C}=\mathrm{C}$ peak at $1600 \mathrm{~cm}^{-1}$ was also observed on this sample. The increase in intensity of the peak associated with the $\mathrm{C}-\mathrm{O}$ stretching mode of the vinyl alcohol groups $\left(1085 \mathrm{~cm}^{-1}\right)$ does not appear to be linked to an increase in vinyl alcohol content since the corresponding $\mathrm{O}-\mathrm{H}$ stretching modes $\left(3350\right.$ and $\left.3450 \mathrm{~cm}^{-1}\right)$ did not significantly change in intensity.

On the filled VCE material, gamma irradiation induced a decrease in the intensity of the stretching and bending modes from vinyl acetate groups and of the stretching modes from methylene backbone, consistent with the release of acetic acid and a lowered mobility of the methylene groups (Figure 4). Similar observations were made on thermally-aged VCE samples (Figure 5).

It should be noted that the ATR method measures IR absorption of an evanescent wave in the sample, primarily analyzing the surface chemistry of the sample and minimizing bulk effects. 
This may explain why the intensity of some of the effects of radiation and temperature aging are small.

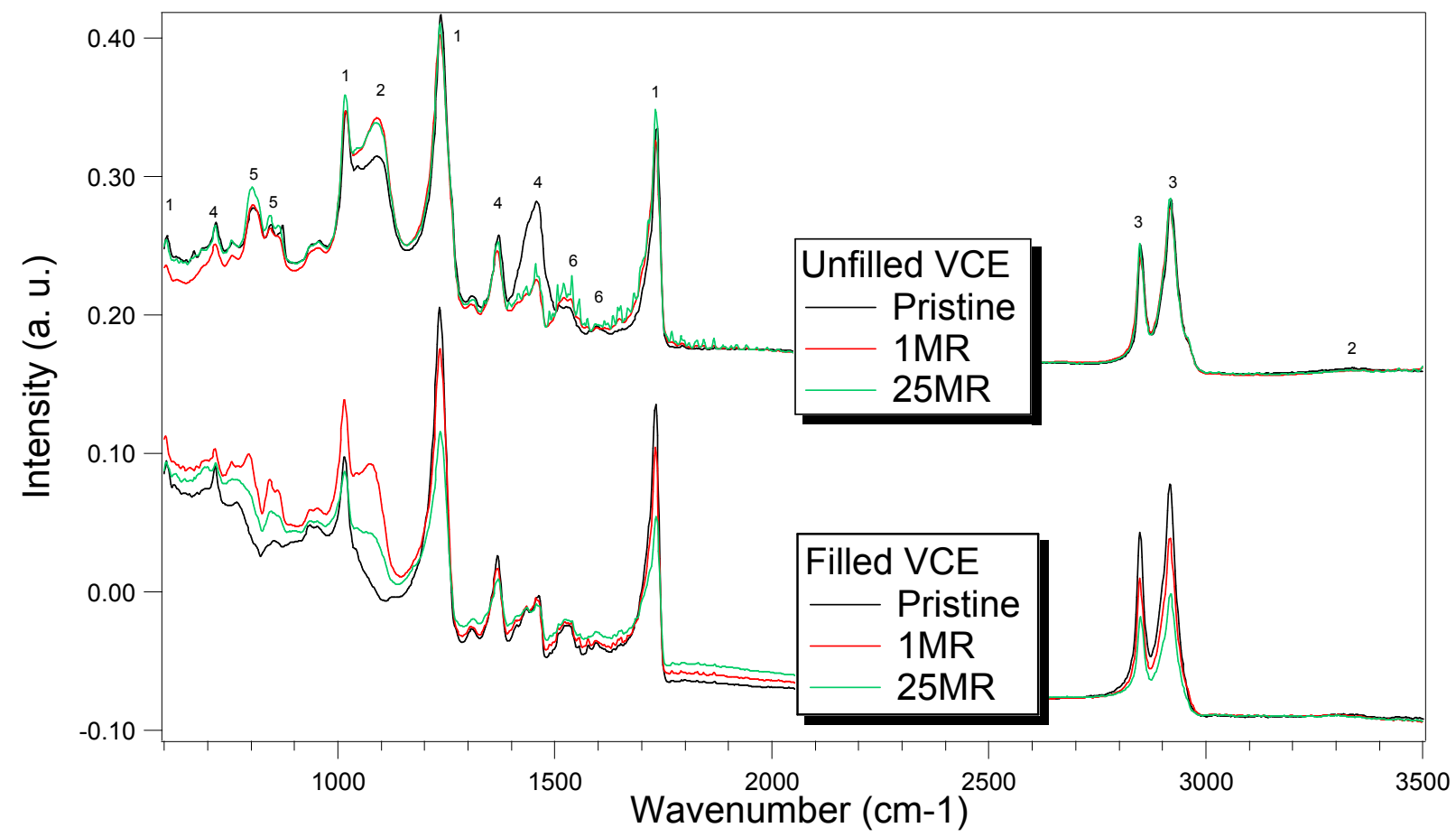

Figure 4. IR spectra of filled and unfilled VCE samples exposed to 0, 1 and 25 MR gamma irradiation.

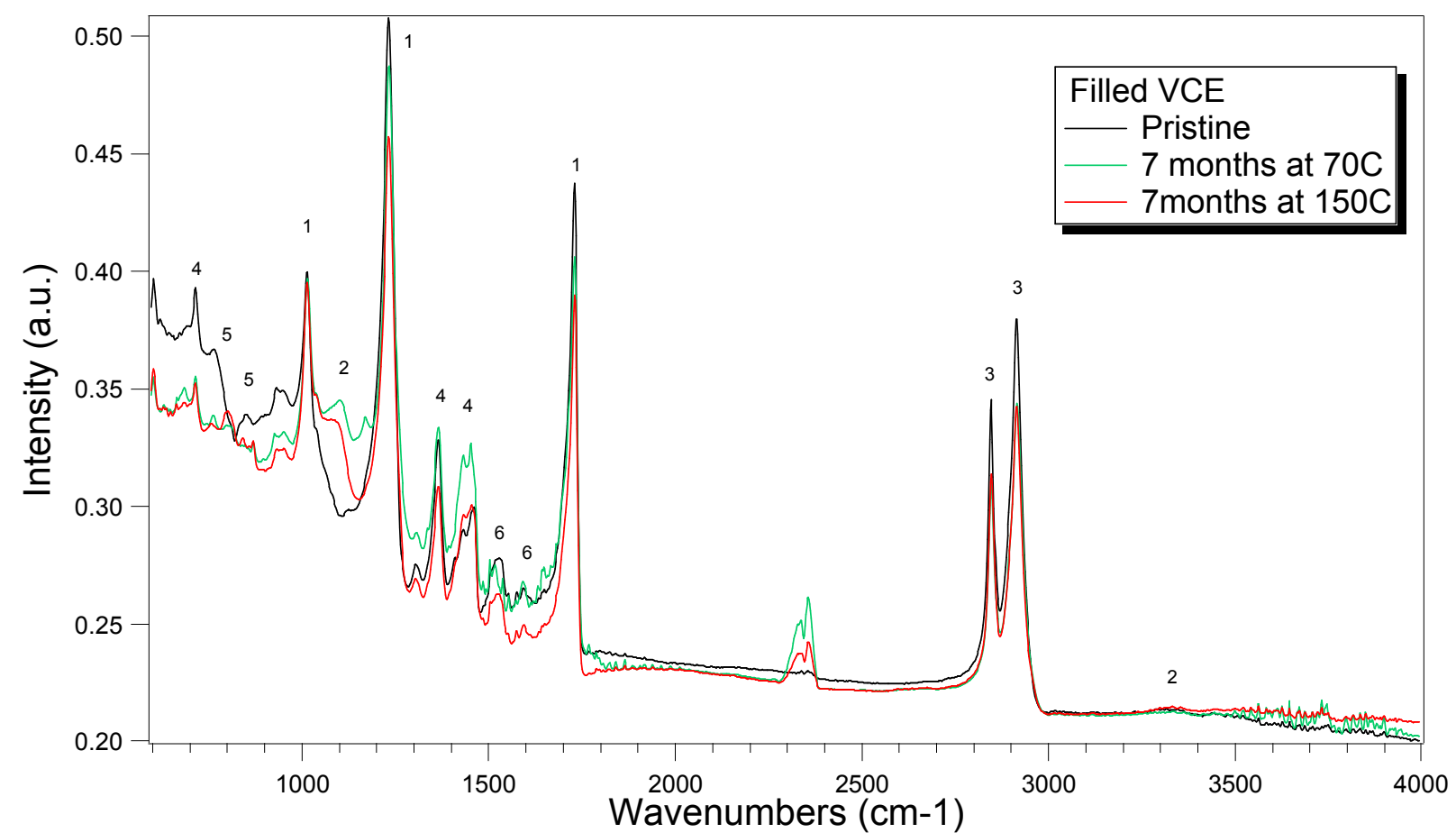

Figure 5. IR spectra of filled VCE samples exposed to temperatures of 20,70 and $150^{\circ} \mathrm{C}$ for 7 months, under inert atmosphere. 


\subsection{Degradation Mechanism}

Experimental results described in the FY09 report as well as in the present report show that the VCE terpolymer outgases acetic acid upon gamma irradiation and thermal treatment. This deacetylation was associated with: a loss of mass corresponding to the weight fraction of vinyl acetate in the VCE material, [5] a red shift of the material's visible absorption (an absorption band centered at $375 \mathrm{~nm}$ was recorded for thermally-treated VCE), [5] a strongly hindered methylene backbone IR deformation mode for unfilled VCE (a decrease in the intensity of the stretching and bending modes from vinyl acetate groups and of the stretching modes from methylene backbone for filled VCE), and an increase in Yong's modulus. Although the deacetylation mechanism with the lowest activation energy (experimental $\mathrm{Ea} \sim 90 \mathrm{KJ}^{\mathrm{mol}} \mathrm{l}^{-1}$ for EVA with $33 \%$ VA content) [9] is the simple hydrolysis of the vinyl acetate group (which releases acetic acid while forming a vinyl alcohol group), this mechanism does not account for the observed yellowing of the material nor for the hindered methylene deformation modes. In addition, experiments performed on dry samples maintained in inert conditions showed a release of acetic acid and a yellowing of the material, when only traces of water were available for the hydrolysis reaction. An alternate deacetylation mechanism, with higher activation energy (Ea $180 \mathrm{KJ}^{\mathrm{m}} \mathrm{mol}^{-1}$ for EVA with $33 \% \mathrm{VA}$ content), [6] is the process in which a hydrogen atom from the ethylene backbone moves to the acetate group to form acetic acid, inserting a $\mathrm{C}=\mathrm{C}$ double bond into the backbone of the polymer chain, adjacent to the $\mathrm{C}$ atom where the leaving group was formerly attached. When propagating to adjacent vinyl acetate groups, this mechanism releases acetic acid while forming alternating single and double bonds (polyenes, $(-\mathrm{C}=\mathrm{C})_{\mathrm{n}}$ ) in the polymer backbone. Such a mechanism (see Figure 6) does not require the presence of water and would explain the release of acetic acid, the red-shift in absorption due to polyene formation (polyenes with $\mathrm{n}=4-6$ typically generate absorption bands in the $250-400 \mathrm{~nm}$ range), $[7,8]$ the frustrated methylene IR deformation modes due to steric hindrance, as well as the stiffening of the material.

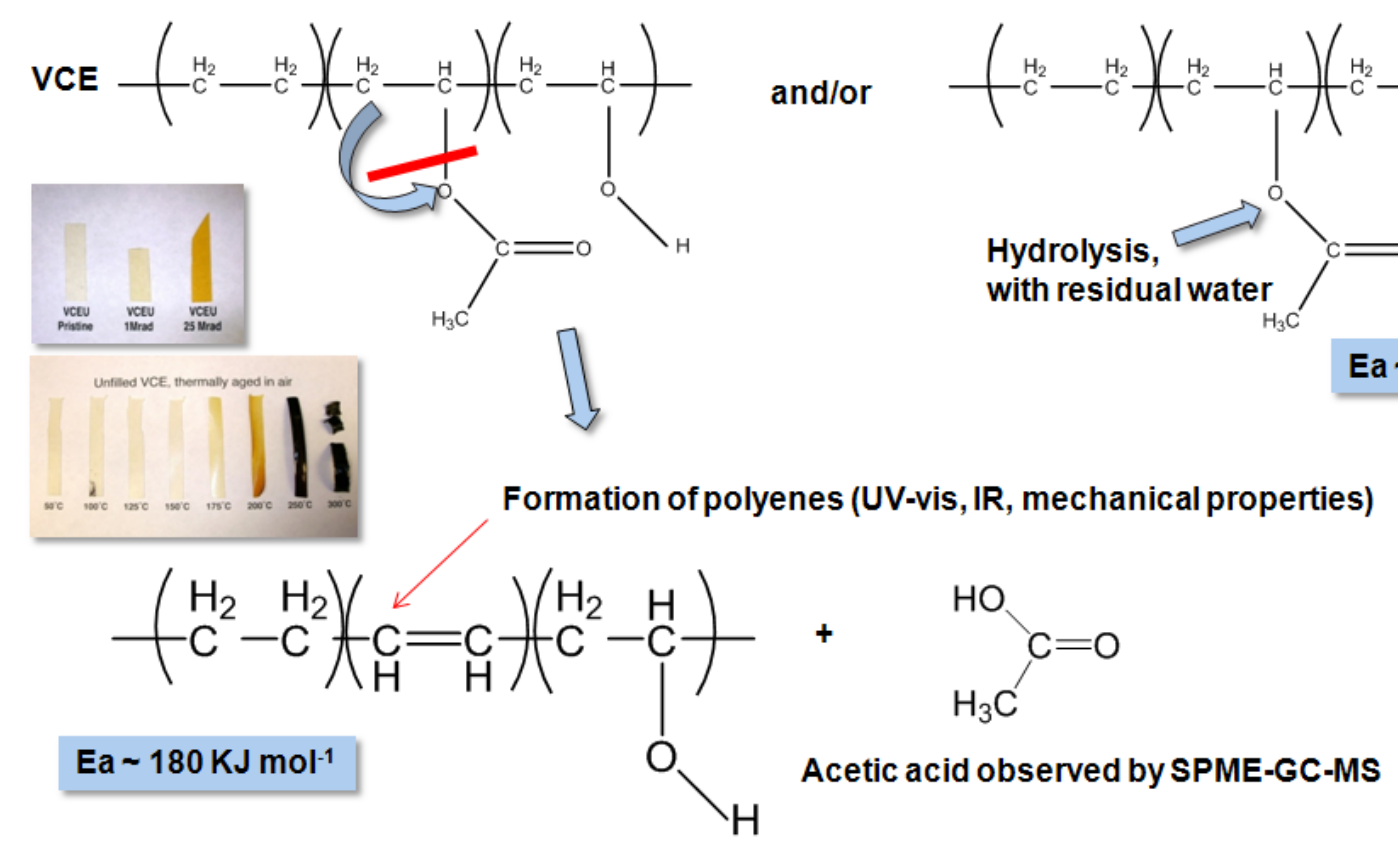

Figure 6. Degradation mechanisms for VCE. 
Collaborative work started with Dr. M. Read and Dr. D. Plant from AWE to perform Density Function Theory simulations of the deacetylation reaction and to provide the lowest energy configurations of the VCE terpolymer after removal of the acetate group. Preliminary results predict hindered IR deformation modes on the methylene backbone after addition of the $\mathrm{C}=\mathrm{C}$ bonds in the background, which is consistent with the experimental IR results obtained on aged VCE samples. Experimental work will also be conducted in collaboration with AWE to detect the $\mathrm{C}=\mathrm{C}$ double bond formation by NMR spectroscopy.

\section{Conclusion}

Experiments performed in FY10 included SPME-GC-MS, mechanical testing, toluene swelling and IR spectroscopy on both filled and unfilled VCE materials aged with gamma radiation and thermal treatments.

Experimental results described in the FY09 report, as well as in the present report, show that the VCE terpolymer outgases acetic acid upon gamma irradiation and thermal treatment. This deacetylation was associated with a loss of mass corresponding to the weight fraction of vinyl acetate in the VCE material, a red shift of the material's visible absorption (an absorption band centered at $375 \mathrm{~nm}$ was recorded for thermally-treated VCE), a strongly hindered methylene backbone IR deformation mode for unfilled VCE (a decrease in the intensity of the stretching and bending modes from vinyl acetate groups and of the stretching modes from methylene backbone for filled VCE), and an increase in Yong's modulus. A model based on the formation of a $\mathrm{C}=\mathrm{C}$ bond in the methylene backbone upon abstraction of the acetate group is proposed, which is consistent with the experimental observations.

\section{Future work}

FY11 will be focused on finalizing a manuscript in collaboration with the AWE group, and on studying various sets of VCE part returns. The parts will have resided in various systems for various periods of time. We will use tensile testing, durometer analysis, Differential Scanning Calorimetry, Toluene Swelling tests, Nuclear Magnetic Resonance, and Infra-Red spectroscopy to analyze the parts and provide information on their aging in actual systems.

\section{References}

1. W.E. Cady, Transition temperatures and crystallinity in EVA, VCE, and Rattan C, LLNL report UCID-15424 (1969).

2. P.M. Wilson, D.A. Spieker, Enhanced Surveillance of Filled Elastomers, KCP report KCP-613-6004 (1997).

3. E.A. Eastwood, D.E. Bowen, VCE replacement development: characterization of EVA materials, KCP report KCP-613-6929 (2004).

4. E.A. Eastwood, VCE replacement development: curing studies, KCP report KCP-6138161 (2006). 
5. S.E. Létant, J. L. Herberg, C.T. Alviso, W. Small IV, H. A. Mulcahy, M. Pearson, T.S. Wilson, S.C. Chinn, and R.S. Maxwell, Aging Studies of Filled and Unfilled VCE. LLNL report LLNL-TR-420245 (2009).

6. T. R. Hull, D. Price, Y. Liu, C. L. Wills and J. Brady, An investigation into decomposition and burning behavior of ethylene-vinyl acetate copolymer nanocomposite materials, Polymer degradation and stability, 82 365-371 (2003).

7. F. J. Pern and A.W. Czanderna, Characterization of ethylene vinyl acetate (EVA) encapsulant: Effect of thermal processing and weathering degradation on its discoloration, Solar Energy Materials and Solar Cells, 25 3-23 (1992).

8. K. Maruyama, Y. Kuramoto, M. Yagi and Y. Tanizaki, Extraction of absorption spectra of some polyenes produced in poly(vinyl alcohol) film utilizing photodegradations by monochromatic light, Polymer, 292429 (1988). 